\title{
Does androgen deprivation therapy in patients with prostate cancer protect from COVID-19?
}

\author{
(iD)oão Paulo Pretti Fantin ${ }^{1}$ \\ (D) Maria Fernanda Warick Facio² \\ (iD) Ana Clara Nagle Spessoto ${ }^{3}$ \\ (iD Luís Cesar Fava Spessoto ${ }^{4}$ \\ (iD) Fernando Nestor Facio Junior ${ }^{4}$
}

\begin{abstract}
1. Doutorando, Programa de Ciências da Saúde, Faculdade de Medicina (FAMERP), São losé do Rio Preto, SP, Brasil. 2. Médica, Faculdade de Medicina (FACERES), São José do Rio Preto, SP, Brasil. 3. Graduanda, Faculdade de Medicina de Catanduva (UNIFIPA), Catanduva, SP, Brasil. 4. Professor de Urologia, Departamento de Urologia, Faculdade de Medicina (FAMERP/FUNFARME), São José do Rio Preto, SP, Brasil.
\end{abstract}

KEYWORDS: Androgen; COVID-19; prostate cancer.

Since the end of 2019, with the disease caused by the new coronavirus in China spreading throughout the world, the entire scientific community has been focused on the search for medications that can minimize severe forms of the disease. Simultaneous research is being developed on the effect of several drugs, such as chloroquine, hydroxychloroquine, antiviral drugs, corticosteroids, antibodies, plasma transfusions, and initial vaccine testing. ${ }^{1}$. However, no studies have been able to find an effective medication for treatment that is better than the immune response of each organism.

Previous data have revealed a greater susceptibility of men to the coronavirus than women ${ }^{2}$. An Italian study directed its attention at testosterone after assessing patients at 68 hospitals in the region of Veneto, where the majority of severe cases in need of hospitalization (60\%) and intensive care (78\%) were men $^{3}$. The authors demonstrated that men with cancer affected by the coronavirus had more severe forms of the disease. However, after analyzing patients with prostate cancer, they found that the rates of infection by COVID-19 were five times lower among those in androgen deprivation therapy (ADT) compared to those with prostate cancer not undergoing this type of therapy (OR 4.05; 95\% CI 1.55 to $10.59)^{3}$.

These findings led to the molecular evaluation of the gene transmembrane protease, serine 2 (TMPRSS2), which is involved in numerous physiological and pathological processes, including cancer and viral infection ${ }^{4}$. This gene is highly expressed in localized and metastatic prostate cancer and its transcription is regulated by androgen receptors $(\mathrm{ARs})^{5}$. It has been demonstrated that ARs regulate the expression of TMPRSS2 in non-prostatic tissues as well, including the lung. In vitro and in vivo results have shown that the administration of androgens 
induces the expression of TMPRSS2 in epithelial cells of the human lung, and the suppression of androgens reduces the transcription of TMPRSS2 in the murine lung $^{6}$. Therefore, this regulation may explain the increased susceptibility of men to developing a severe infection by SARS-CoV-2 compared to women.

However, it is possible that the greater social distancing of patients undergoing ADT plays a role in the lower frequency of COVID-19 among such patients. The data need to be validated in large cohorts correcting for other variables, such as cardiometabolic comorbidities and obesity ${ }^{3}$. Therefore, it seems far too soon to declare that ADT for men in treatment for prostate cancer has a protective effect with regards to COVID-19.

Since the expression of the TMPRSS2 gene may be related to a lower infection rate by COVID-19 in men undergoing ADT, randomized, controlled clinical trials are needed to confirm or refute the hypothesis that androgen deprivation protects patients with prostate cancer from COVID-19.

\section{Conflicts of interest}

The authors have nothing to disclose

Author's Contribution

All authors have contributed equally to the work.

\section{REFERENCES}

1. Zhai $P$, Ding $Y$, Wu $X$, Long I, Zhong $Y$, Li Y. The epidemiology, diagnosis and treatment of COVID-19. Int J Antimicrob Agents. 2020;55(5):105955.

2. Zhou F, Yu T, Du R, Fan G, Liu Y, Liu Z, et al. Clinical course and risk factors for mortality of adult inpatients with COVID-19 in Wuhan, China: a retrospective cohort study. Lancet. 2020;395(10229):1054-62.

3. Montopoli M, Zumerle S, Vettor R, Rugge M, Zorzi M, Catapano CV, et al. Androgen-deprivation therapies for prostate cancer and risk of infection by SARS-CoV-2: a population-based study ( $N=4532)$. Ann Oncol. 2020;31(8):1040-5.

4. Shin WJ, Seong BL. Type II transmembrane serine proteases as potential target for anti-influenza drug discovery. Expert Opin Drug Discov. 2017;12(11):1139-52.

5. Lucas |M, Heinlein C, Kim T, Hernandez SA, Malik MS, True LD, et al. The androgen-regulated protease TMPRSS2 activates a proteolytic cascade involving components of the tumor microenvironment and promotes prostate cancer metastasis. Cancer Discov. 2014;4(11):1310-25.

6. Mikkonen L, Pihlajamaa P, Sahu B, Zhang FP, Jänne OA. Androgen receptor and androgen-dependent gene expression in lung. Mol Cell Endocrinol. 2010;317(1-2):14-24 